\title{
Interim 2017/18 influenza seasonal vaccine effectiveness: combined results from five European studies
}

Marc Rondy ${ }^{1,2}$, Esther Kissling, ${ }^{1,2}$, Hanne-Dorthe Emborg 3 , Alin Gherasim4, Richard Pebody5, Ramona Trebbien6, Francisco Pozo7, Amparo Larrauri ${ }^{4}$, Jim McMenamin ${ }^{8}$, Marta Valenciano' ${ }^{1}$ I-MOVE/I-MOVE+ group ${ }^{9}$

1. EpiConcept, Paris, France

2. MR and EK contributed equally to the study and manuscript writing

3. Department of Infectious Disease Epidemiology and Prevention, Statens Serum Institut, Copenhagen, Denmark

4. National Epidemiology Centre, Institute of Health Carlos III, Madrid Spain; CIBER de Epidemiología y Salud Pública (CIBERESP), Institute of Health Carlos III, Madrid Spain

5. Public Health England, London, United Kingdom

6. Department of Virus and Microbiological Special diagnostics, National Influenza Center, Statens Serum Institut, Copenhagen, Denmark

7. Inmaculada Casas National Centre for Microbiology, National Influenza Reference Laboratory, World Health Organization National Influenza Centre, Institute of Health Carlos III

8. Health Protection Scotland, Glasgow, United Kingdom

9. The members of the I-MOVE/I-MOVE+ group are listed at the end of the article

Correspondence: Marc Rondy (m.rondy@epiconcept.fr)

Citation style for this article:

Rondy Marc, Kissling Esther, Emborg Hanne-Dorthe, Gherasim Alin, Pebody Richard, Trebbien Ramona, Pozo Francisco, Larrauri Amparo, McMenamin Jim

Valenciano Marta, I-MOVE/I-MOVE+ group. Interim 2017/18 influenza seasonal vaccine effectiveness: combined results from five European studies. Euro Surveill. 2018;23(9):pii=18-00086. https://doi.org/10.2807/1560-7917.ES.2018.23.9.18-00086

Article submitted on 26 Feb 2018 / accepted on 01 Mar 2018 / published on 01 Mar 2018

Between September 2017 and February 2018, influenza $A\left(\mathrm{H}_{1} \mathrm{~N}_{1}\right)$ pdmo9, $A\left(\mathrm{H}_{3} \mathrm{~N}_{2}\right)$ and $B$ viruses (mainly $B / Y a m a g a t a$, not included in 2017/18 trivalent vaccines) co-circulated in Europe. Interim results from five European studies indicate that, in all age groups, $2017 / 18$ influenza vaccine effectiveness was 25 to $52 \%$ against any influenza, 55 to $68 \%$ against influenza $A\left(\mathrm{H}_{1} \mathrm{~N}_{1}\right)$ pdmo9, -42 to $7 \%$ against influenza $A\left(\mathrm{H}_{3} \mathrm{~N}_{2}\right)$ and 36 to $54 \%$ against influenza B. 2017/18 influenza vaccine should be promoted where influenza still circulates.

Most countries in the European Union (EU) recommend and fund seasonal influenza vaccine for elderly people and individuals at increased risk of severe influenza [1]. The United Kingdom (UK) commenced the incremental introduction of a universal childhood influenza vaccination programme in 2013/14 using a quadrivalent live attenuated influenza vaccine (LAIV4) for healthy children and quadrivalent inactivated vaccine (QIV) for atrisk children for whom LAIV4 is contraindicated [2].

The trivalent influenza vaccines for the 2017/18 northern hemisphere influenza season include an A/Michigan/45/2015 ( $\left.\mathrm{H}_{1} \mathrm{~N}_{1}\right)$ pdmog-like virus, an A/Hong Kong/4801/2014 ( $\left.\mathrm{H}_{3} \mathrm{~N}_{2}\right)$-like virus and a $\mathrm{B} /$ Brisbane/60/2008-like virus (B/Victoria lineage). The quadrivalent vaccines also contain a $B /$ Phuket/3073/2013-like virus (B/Yamagata lineage) [3]. The early phase of the $2017 / 18$ influenza season in Europe was characterised by the co-circulation of influenza $A\left(\mathrm{H}_{1} \mathrm{~N}_{1}\right)$ pdmog, influenza $A\left(\mathrm{H}_{3} \mathrm{~N}_{2}\right)$ and influenza
$B$, with different patterns of dominant type or subtype observed between countries [4]. Up to February 2018, most influenza B viruses assigned to a lineage were B/ Yamagata viruses, not included in the $2017 / 18$ trivalent vaccine $[3,4]$.

Here we present the interim 2017/18 season influenza vaccine effectiveness (VE) estimates from three singlecountry studies (UK, Denmark (DK) and Spain (ES)) and two multi-country studies (primary care (EU-PC) and hospital (EU-H) European Influenza - Monitoring Vaccine Effectiveness (I-MOVE/I-MOVE+) networks) (Figure 1).

\section{Study design and estimation of vaccine effectiveness}

The methods of these five studies have been described in detail elsewhere [5-9]. Study sites included in EU-PC (Croatia, France, Germany, Ireland, Italy, the Netherlands, Portugal, Spain and Sweden) and EU-H (France, Italy, the Netherlands, Portugal and Spain) followed generic protocols for primary care-based or hospital-based studies.

All five studies used a test-negative case control design (TND) [10]. In short, individuals presenting at participating healthcare settings with a pre-determined set of symptoms (including at least one systemic and one respiratory symptom) were swabbed. Samples were tested for influenza using RT-PCR. Individuals testing positive for influenza were classified as cases (by influenza (sub)type), those testing negative as controls. 


\section{FIGURE 1}

European Union countries contributing to the influenza vaccine effectiveness results presented, by study, 2017/18 $(\mathrm{n}=21,220)$

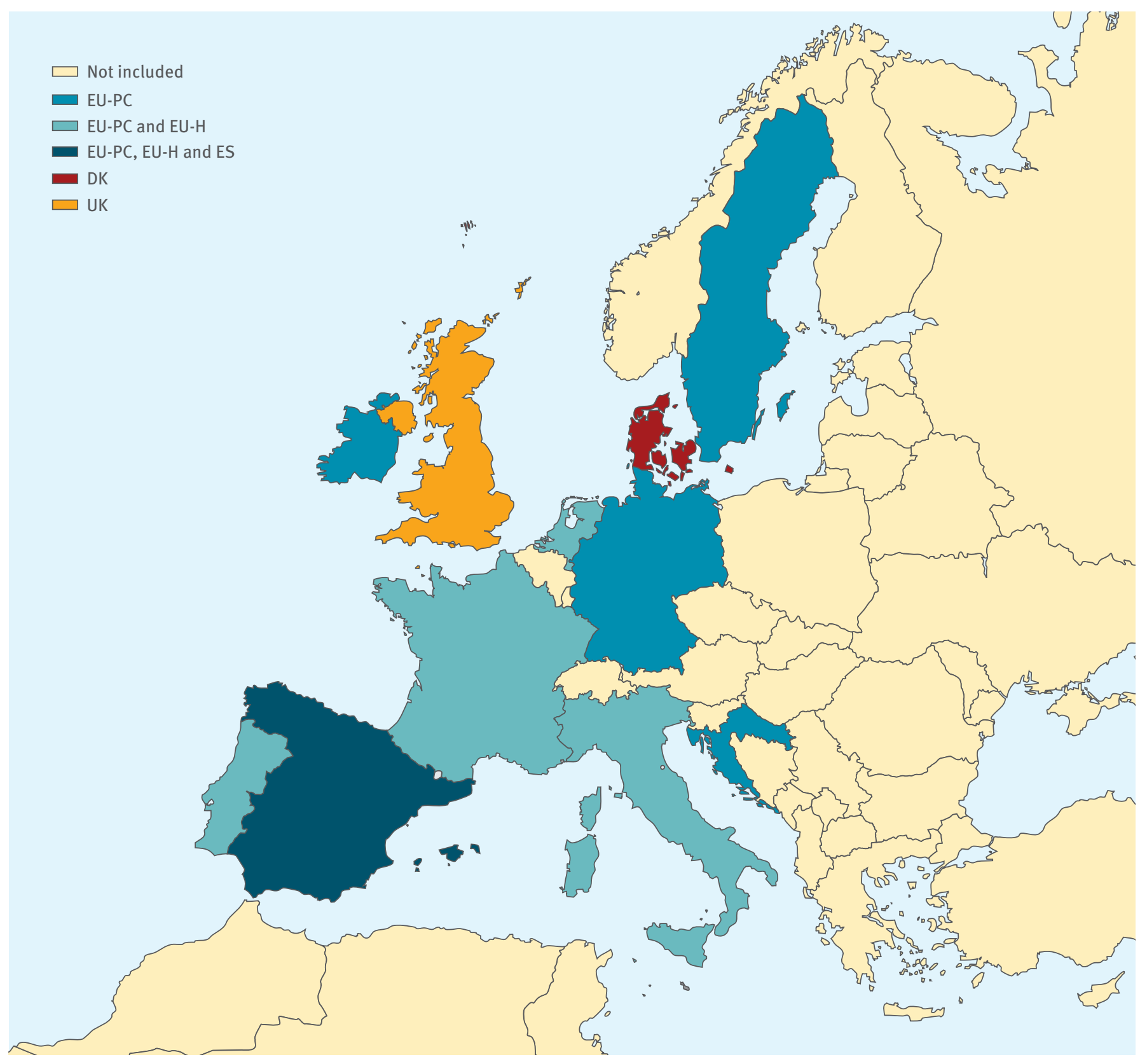

DK: Denmark study; ES: Spain study; EU-H: European hospital-based multi-country I-MOVE+study; EU-PC: European primary care-based multi-country I-MOVE/I-MOVE+ study; UK: United Kingdom study.

The ES, UK and EU-PC studies included patients at primary care level (henceforth referred to as medically attended), the EU-H study included patients at hospital level (henceforth referred to as hospitalised), and the DK study included results from primary care and hospital level pooled together. Patients' inclusion was foreseen to be systematic (or exhaustive) in the ES, EU-PC and EU-H studies and ad hoc in the DK and UK studies. In Spain, 268 of the 833 physicians included in the ES study were also included in the EU-PC study.
The study population included all age groups in all studies except for EU-H, which was confined to individuals 65 years and older.

In all studies, we defined patients as vaccinated with the 2017/18 influenza vaccine if they had been vaccinated at least 14 days (UK) or 15 days (all other studies) before symptom onset. Patients were excluded if they were vaccinated less than 14 (UK) or 15 days (all other studies) before symptom onset or if the date of vaccination was unknown. 


\section{FIGURE 2}

Proportion of influenza (sub)types by study, Europe, $2017 / 18(n=6,979)$

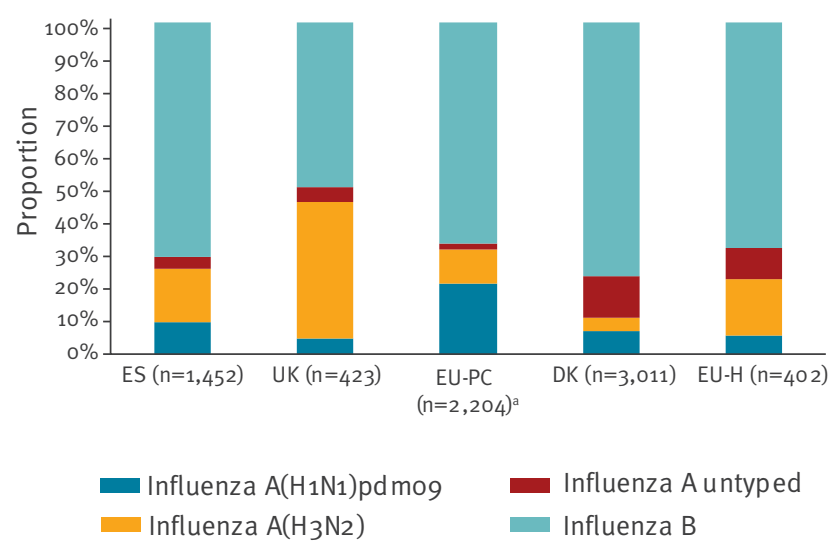

DK: Denmark study; ES: Spain study; UK: United Kingdom study; EU-H: European hospital-based multi-country l-MOVE+study; EU-PC: European primary care-based multi-country I-MOVE/IMOVE+ study.

a Includes two influenza $\mathrm{A}\left(\mathrm{H}_{1} \mathrm{~N}_{1}\right)$ pdmo9/B co-infections; 98 of influenza $A\left(\mathrm{H}_{1} \mathrm{~N}_{1}\right)$ pdmo9, 122 of $A\left(\mathrm{H}_{3} \mathrm{~N}_{2}\right)$ and 454 of $B$ cases were also in ES.

The graph includes individuals excluded from the VE analysis due to missing covariates.

In seven EU-PC countries (France, Germany, Ireland, the Netherlands, Portugal, Spain and Sweden), the UK, ES and DK, all or a random sample of positive influenza specimens were selected for genetic sequencing.

VE was computed by comparing the odds of vaccination between cases and controls (VE $=(1-O R) \times 100)$. All studies used logistic regression to adjust VE for measured confounding variables, excluding patients with missing data for covariates in the model (complete case analysis) (Table 1). We computed VE overall and, where possible, by age group and target population (as defined locally in the various studies and study sites) against any influenza, influenza $A\left(\mathrm{H}_{3} \mathrm{~N}_{2}\right)$, influenza $A\left(\mathrm{H}_{1} \mathrm{~N}_{1}\right)$ pdmo9, any influenza $B$ and influenza $B /$ Yamagata.

If the number of events per parameter was lower than 10, we conducted a sensitivity analysis using penalised logistic regression to assess small sample bias [11].

\section{Results}

Between September 2017 and February 2018, the number of patients included in the VE analysis by study was 2,399 (1,452 cases) in the ES, 1,331 (421 cases) in the UK, 4,652 (2,103 cases) in the EU-PC, 11,907 (3,011 cases) in the DK and 931 (385 cases) in the EU-H study. Overall, more than two thirds of cases were positive for influenza $B$ viruses in all studies except UK, where influenza $A$ and $B$ viruses were detected in similar proportions (51\% (214/423) and 49\% (209/423), respectively) (Figure 2). Where subtyped, influenza $A$ viruses were mainly $A\left(\mathrm{H}_{3} \mathrm{~N}_{2}\right)$ in $\mathrm{ES}(62 \%$ (233/375) of subtyped influenza A specimens), UK (90\% (174/194)) and EU-H (74\% (68/92)), and mainly $\mathrm{A}\left(\mathrm{H}_{1} \mathrm{~N}_{1}\right)$ pdmog in DK (56\% (145/257)) and EU-PC (67\% (469/698)).

\section{Any influenza}

Among all ages, VE against any medically attended influenza ranged between $25 \%$ (95\% confidence interval $(\mathrm{Cl}):-10$ to 48$)$ in the UK study and $52 \%(95 \% \mathrm{Cl}$ : 29 to 67 ) in the ES study. In UK, VE of the LAIV4 was $53 \%(95 \% \mathrm{Cl}:-56$ to 86$)$ in children and VE of the inactivated vaccine was $18 \%(95 \% \mathrm{Cl}:-23$ to 45 ) in adults (Table 2). Among the target groups for influenza vaccination, the VE was $36 \%(95 \% \mathrm{Cl}: 13$ to 53 ) in EU-PC and $40 \%$ (95\% Cl: 1 to 63 ) in the ES study. In EU-H, VE against any hospitalised influenza in patients aged 65 years and older was 35\% (95\% Cl: 13 to 51$)$.

\section{Influenza $\mathrm{A}(\mathrm{H} 1 \mathrm{~N} 1) \mathrm{pdm} 09$}

All 76 influenza $A\left(\mathrm{H}_{1} \mathrm{~N}_{1}\right)$ pdmog viruses sequenced belonged to clade 6B.1 (A/Michigan/45/2015) (Table 2). VE against influenza $A\left(\mathrm{H}_{1} \mathrm{~N}_{1}\right)$ pdmog was $68 \%(95 \% \mathrm{Cl}$ : 42 to 83 ) and $55 \%(95 \% \mathrm{Cl}: 23$ to 74 ) among all ages in the EU-PC and DK studies, respectively. Among 18-64 year-olds, it was $63 \%(95 \% \mathrm{Cl}: 12$ to 84$)$ and $60 \%(95 \%$ $\mathrm{Cl}: 13$ to 82 ) in the EU-PC and DK studies, respectively. Among those aged 65 years and older, it was 37\% (95\% $\mathrm{Cl}:-40$ to 72 ) in the DK study (Table 2 ).

\section{Influenza $\mathrm{A}(\mathrm{H} 3 \mathrm{~N} 2)$}

Of the 204 influenza $A\left(\mathrm{H}_{3} \mathrm{~N}_{2}\right)$ viruses sequenced, 63\% $(n=129)$ belonged to genetic clade 3 C.2a, $35 \%(n=72)$ to 3 C.2a1 and $1 \%(n=3)$ to 3 C.3a (Table 3$)$.

Among all ages, VE against influenza $\mathrm{A}\left(\mathrm{H}_{3} \mathrm{~N}_{2}\right)$ ranged from $-42 \%$ (95\% Cl: -116 to 7 ) in the DK and $7 \%$ (95\% $\mathrm{Cl}:-74$ to 51$)$ in the ES study. VE against hospitalisation for influenza $\mathrm{A}\left(\mathrm{H}_{3} \mathrm{~N}_{2}\right)$ in patients aged 65 years and older was $-1 \%$ (95\% Cl: -93 to 47 ) in EU-H (Table 2 ).

\section{Influenza B}

Of the 596 influenza B viruses sequenced, 94\% $(n=559)$ were $B /$ Yamagata (all belonging to clade 3 influenza $B /$ Phuket/3073/2013) and $6 \%(n=37)$ were influenza $B /$ Victoria (25 belonging to clade $1 A \Delta\left(K_{162}\right.$, $\mathrm{N} 163$ ) and 12 belonging to clade $1 \mathrm{~A}$ ) (Table 3).

Among all ages, VE against influenza $B$ ranged between $36 \%(95 \% \mathrm{Cl}: 27$ to 44$)$ in the DK and $54 \%(95 \% \mathrm{Cl}$ : 24 to 72 ) in the UK study. Age group-specific VE was lowest at $15 \%(95 \% \mathrm{Cl}:-114$ to 66$)$ among those aged 65 years and older and highest at $83 \%(95 \% \mathrm{Cl}: 54$ to 94 ) in the 0-14-year age group in the ES study. VE was $34 \%$ (95\% Cl: 8 to 52 ) against hospitalised influenza $\mathrm{B}$ in $\mathrm{EU}-\mathrm{H}$ and $28 \%$ (95\% Cl: 14 to 39 ) against medically attended and hospitalised influenza B in the DK study among those aged 65 years and older (Table 2). VE against influenza B/Yamagata was 77\% (95\% Cl: 14 to 94 ) in the ES study and $49 \%(95 \% \mathrm{Cl}: 19$ to 67$)$ in EU-PC (Table 2). 
Summary characteristics of the influenza vaccine effectiveness studies included, Europe, influenza season 2017/18 $(\mathrm{n}=21,220)$

\begin{tabular}{|c|c|c|c|c|c|}
\hline & ES & UK & EU-PC & DK & $\mathrm{EU}-\mathrm{H}$ \\
\hline Study period & $\begin{array}{l}30 \text { Oct } 2017 \text { to } \\
21 \text { Jan } 2018\end{array}$ & $\begin{array}{c}1 \text { Oct } 2017 \text { to } 14 \text { Jan } \\
2018\end{array}$ & $\begin{array}{c}25 \text { Sep } 2017 \text { to } 26 \text { Jan } \\
2018\end{array}$ & 1 Dec 2017 to 5 Feb 2018 & 25 Oct 2017 to 4 Feb 2018 \\
\hline Setting & Primary care & Primary care & Primary care & Primary care and hospital & Hospital \\
\hline Location & Spain & $\begin{array}{c}\text { England, Scotland, } \\
\text { Northern Ireland and } \\
\text { Wales }\end{array}$ & $\begin{array}{l}\text { Croatia, France, Germany, } \\
\text { Ireland, Italy, the } \\
\text { Netherlands, Portugal, } \\
\text { Spain and Sweden }\end{array}$ & Denmark & $\begin{array}{c}\text { France, Italy, the } \\
\text { Netherlands, Portugal and } \\
\text { Spain }\end{array}$ \\
\hline Study design & TND & TND & TND & TND & TND \\
\hline Data source & $\begin{array}{l}\text { Sentinel } \\
\text { physicians and } \\
\text { laboratory }\end{array}$ & $\begin{array}{l}\text { Sentinel physicians } \\
\text { and laboratory }\end{array}$ & $\begin{array}{l}\text { Sentinel physicians and } \\
\text { laboratory }^{\mathrm{a}}\end{array}$ & $\begin{array}{l}\text { Data linkage of Danish } \\
\text { Microbiology Database, } \\
\text { the Danish Vaccination } \\
\text { Register and the Danish } \\
\text { National Hospital Register }\end{array}$ & $\begin{array}{c}\text { Hospital charts, vaccine } \\
\text { registers, interviews } \\
\text { with GPs/pharmacists, } \\
\text { laboratory }\end{array}$ \\
\hline $\begin{array}{l}\text { Age group } \\
\text { of study } \\
\text { population }\end{array}$ & All & All & $\geq 6$ months & $\geq 18$ years & $\geq 65$ years \\
\hline $\begin{array}{l}\text { Case } \\
\text { definition }\end{array}$ & ILI & ILI & ILI & ILI & SARI \\
\hline $\begin{array}{l}\text { Selection of } \\
\text { patients }\end{array}$ & Systematic & $\begin{array}{l}\text { At practitioner's } \\
\text { discretion }\end{array}$ & Systematic & $\begin{array}{l}\text { At practitioner's } \\
\text { discretion }\end{array}$ & Exhaustive \\
\hline $\begin{array}{l}\text { Vaccine types } \\
\text { used }^{\mathrm{b}}\end{array}$ & $\begin{array}{l}\text { Mostly TIV (no } \\
\text { individual data) }\end{array}$ & $\begin{array}{c}\text { In children: } 19 \% \text { TIV, } \\
77 \% \text { LAIV4 nasal } \\
\text { spray, } 3 \% \text { unknown } \\
\text { In adults: } 100 \% \\
\text { unknown }\end{array}$ & $\begin{array}{c}67 \% \text { TIV, } 17 \% \text { unknown, } \\
8 \% \text { TIV adjuvanted, } 4 \% \\
\text { QIV, 3\% TIV intradermal, } \\
\text { 1\% LAIV4 nasal spray }\end{array}$ & $\begin{array}{l}\text { Only TIV (no individual } \\
\text { data) }\end{array}$ & $\begin{array}{l}57 \% \text { TIV, } 25 \% \text { unknown, } \\
8 \% \text { TIV adjuvanted, } 10 \% \\
\text { TIV intradermal }\end{array}$ \\
\hline $\begin{array}{l}\text { Variables of } \\
\text { adjustment }\end{array}$ & $\begin{array}{l}\text { Age (RCS), } \\
\text { sex, presence } \\
\text { of chronic } \\
\text { conditions, } \\
\text { onset date, } \\
\text { region }\end{array}$ & $\begin{array}{l}\text { Age group, sex, onset } \\
\text { date, pilot area for } \\
\text { child vaccination } \\
\text { programme, } \\
\text { surveillance scheme }\end{array}$ & $\begin{array}{l}\text { Age (RCS), sex, presence } \\
\text { of chronic conditions, } \\
\text { onset date and study site }\end{array}$ & $\begin{array}{l}\text { Age group, sex, presence } \\
\text { of chronic conditions, } \\
\text { onset date }\end{array}$ & $\begin{array}{l}\text { Age (RCS), lung diseases, } \\
\text { heart diseases, diabetes } \\
\text { mellitus, obesity } \\
\text { (BMI } \geq 30 \text { ), renal diseases, } \\
\text { cancer and hospitalisation } \\
\text { in the past } 12 \text { months, } \\
\text { onset date, study site }\end{array}$ \\
\hline
\end{tabular}

DK: Denmark study; ES: Spain study; EU-H: European hospital-based multi-country I-MOVE+study; EU-PC: European primary care-based multi-country I-MOVE/I-MOVE+ study; GP: general practitioner; ILI: influenza-like illness; LAIV4: quadrivalent live attenuated influenza vaccines; LRI: lower respiratory infection; SARI: severe acute respiratory infection; TIV: trivalent inactivated vaccines; TND: test-negative design; RCS: restricted cubic spline; UK: United Kingdom study.

a In Spain, 268 of the 833 physicians included in the ES study were also included in the EU-PC study.

${ }^{b}$ Vaccines were egg-propagated, non-adjuvanted and administered intramuscularly unless otherwise specified.

\section{Sensitivity analyses}

For all of the above analyses, sensitivity analyses for small sample size gave similar results (absolute difference ranging between $1 \%$ and $6 \%$ ).

\section{Discussion}

Interim results from five established influenza VE studies across Europe indicate that 2017/18 VE against all influenza ranged between 25 and $52 \%$ among all ages and between 36 and $40 \%$ in the targeted groups. VE was moderate to good against influenza $A\left(\mathrm{H}_{1} \mathrm{~N}_{1}\right)$ pdmo9 among all ages (55 to 68\%), poor against influenza $\mathrm{A}\left(\mathrm{H}_{3} \mathrm{~N}_{2}\right)$ with all point estimates below $8 \%$ for all ages, and moderate against influenza $B$, with point estimates between 39 and $52 \%$ for all ages.

The good VE against medically attended influenza $\mathrm{A}\left(\mathrm{H}_{1} \mathrm{~N}_{1}\right)$ pdmog is consistent with historical data [12].
However, during the last influenza $\mathrm{A}\left(\mathrm{H}_{1} \mathrm{~N}_{1}\right)$ pdmog season in Europe (2015/16), the EU-PC VE of 33\% against influenza $A\left(\mathrm{H}_{1} \mathrm{~N}_{1}\right)$ pdmog in all age groups was lower than what we report here [13]. In the $2015 / 16$ season, the influenza vaccine strain $A / C a l i f o r n i a / 7 / 2009\left(\mathrm{H}_{1} \mathrm{~N}_{1}\right)$ pdmog differed from the circulating strains which mainly belonged to the genetic subgroup 6B.1 (represented by $A /$ Michigan/45/2015 ( $\left.\mathrm{H}_{1} \mathrm{~N}_{1}\right)$ pdmog). This 6B.1 strain was included in the 2017/18 vaccine and was identified in all $A\left(\mathrm{H}_{1} \mathrm{~N}_{1}\right)$ pdmog samples sequenced in the study sites. The change in vaccine strain may have led to a better $\mathrm{VE}$ against $\mathrm{A}\left(\mathrm{H}_{1} \mathrm{~N}_{1}\right)$ pdmog. More precise end-of-season estimates and results at the hospital level will help investigate this hypothesis.

The influenza $A\left(\mathrm{H}_{3} \mathrm{~N}_{2}\right)$ component included in the 2017/18 northern hemisphere vaccine was the same as in the 2016/17 northern hemisphere vaccine [14]. As anticipated based on EU-H 2016/17 results [15] and 
TABLE 2

Interim adjusted seasonal vaccine effectiveness against any laboratory-confirmed influenza, influenza A(H1N1)pdm09, $\mathrm{A}(\mathrm{H} 3 \mathrm{~N} 2)$ and $\mathrm{B}$, by age group, target group for vaccination and by study, Europe, influenza season 2017/18

\begin{tabular}{|c|c|c|c|c|c|c|c|c|c|c|}
\hline \multirow{2}{*}{$\begin{array}{l}\text { Influenza type/subtype and } \\
\text { study site }\end{array}$} & \multirow{2}{*}{ Setting } & \multirow{2}{*}{ Study population } & \multicolumn{3}{|c|}{ Cases } & \multicolumn{3}{|c|}{ Controls } & \multirow{2}{*}{ Adjusted VE } & \multirow{2}{*}{$95 \% \mathrm{Cl}$} \\
\hline & & & All & Vacc & $\%$ & All & Vacc & $\%$ & & \\
\hline \multicolumn{11}{|l|}{ Influenza A+B } \\
\hline \multirow{5}{*}{ ES } & \multirow{5}{*}{ PC } & All ages & 1,452 & 98 & 7 & 947 & 75 & 8 & 52 & 29 to 67 \\
\hline & & $0-14$ years & 589 & 15 & 3 & 370 & 13 & 4 & 78 & 45 to 91 \\
\hline & & $15-64$ years & 762 & 44 & 6 & 511 & 40 & 8 & 54 & 23 to 73 \\
\hline & & $\geq 65$ years & 101 & 42 & 42 & 66 & 22 & 33 & 21 & -93 to 68 \\
\hline & & Target group ${ }^{\mathrm{a}}$ & 278 & 72 & 26 & 180 & 50 & 28 & 40 & 1 to 63 \\
\hline \multirow{3}{*}{ UK } & \multirow{3}{*}{$\mathrm{PC}$} & All ages & 421 & 93 & 22 & 910 & 190 & 21 & 25 & -10 to 48 \\
\hline & & $2-17$ years $\left(\right.$ LAIV $\left._{4}\right)$ & 69 & 5 & 7 & 166 & 19 & 11 & 53 & -56 to 86 \\
\hline & & $\geq 18$ years (IIV) & 347 & 87 & 25 & 630 & 163 & 26 & 18 & -23 to 45 \\
\hline \multirow{5}{*}{ EU-PC } & \multirow{5}{*}{$\mathrm{PC}$} & All ages & 2,103 & 210 & 10 & 2,549 & 272 & 11 & 38 & 20 to 52 \\
\hline & & $0-17$ years & 846 & 26 & 3 & 998 & 35 & 4 & 59 & 23 to 78 \\
\hline & & $18-64$ years & 1,021 & 74 & 7 & 1,288 & 109 & 8 & 34 & 5 to 54 \\
\hline & & $\geq 65$ years & 234 & 110 & 47 & 262 & 128 & 49 & 44 & 8 to 66 \\
\hline & & Target group $^{\mathrm{a}}$ & 554 & 172 & 31 & 713 & 217 & 30 & 36 & 13 to 53 \\
\hline \multirow{3}{*}{ DK } & \multirow{3}{*}{ PC and hospital } & All ages & 3,011 & 593 & 20 & 8,896 & 2299 & 26 & 34 & 25 to 41 \\
\hline & & $18-64$ years & 1,564 & 136 & 9 & 3,462 & 538 & 16 & 47 & 35 to 58 \\
\hline & & $\geq 65$ years & 934 & 447 & 48 & 3,089 & 1,688 & 55 & 23 & 10 to 34 \\
\hline EU-H & Hospital & $\geq 65$ years & 385 & 200 & 52 & 546 & 332 & 61 & 35 & 13 to 51 \\
\hline \multicolumn{11}{|l|}{ Influenza $\mathrm{A}\left(\mathrm{H}_{1} \mathrm{~N}_{1}\right)$ pdmo9 } \\
\hline & & All ages & 444 & 14 & 3 & 1,999 & 195 & 10 & 68 & 42 to 83 \\
\hline EU-PC & $P C$ & $18-64$ years & 203 & 7 & 3 & 955 & 77 & 8 & 63 & 12 to 84 \\
\hline & & All ages & 214 & 18 & 8 & 8,896 & 2299 & 26 & 55 & 23 to 74 \\
\hline DK & PC and hospital & $18-64$ years & 119 & 7 & 6 & 3,462 & 538 & 16 & 60 & 13 to 82 \\
\hline & & $\geq 65$ years & 26 & 11 & 42 & 3,089 & 1,688 & 55 & 37 & -40 to 72 \\
\hline Influenza $\mathrm{A}\left(\mathrm{H}_{3} \mathrm{~N}_{2}\right)$ & & & & & & & & & & \\
\hline ES & $\mathrm{PC}$ & All ages & 233 & 22 & 9 & 947 & 75 & 8 & 7 & -74 to 51 \\
\hline UK & $\mathrm{PC}$ & All ages & 194 & 58 & 30 & 910 & 190 & 21 & -27 & -111 to 24 \\
\hline & & All ages & 220 & 35 & 16 & 1,505 & 147 & 10 & -16 & -96 to 31 \\
\hline EU-PC & PC & $18-64$ years & 140 & 9 & 6 & 771 & 66 & 9 & 27 & -62 to 67 \\
\hline & & All ages & 122 & 53 & 43 & 8,896 & 2,299 & 26 & -42 & -116 to 7 \\
\hline DK & PC and hospital & $18-64$ years & 45 & 6 & 13 & 3,462 & 538 & 16 & 21 & -95 to 68 \\
\hline & & $\geq 65$ years & 67 & 45 & 67 & 3,089 & 1,688 & 55 & -65 & -178 to 2 \\
\hline EU-H & Hospital & $\geq 65$ years & 60 & 38 & 63 & 242 & 154 & 64 & -1 & -93 to 47 \\
\hline Any influenza B & & & & & & & & & & \\
\hline & & All ages & 1,022 & 72 & 7 & 947 & 75 & 8 & 52 & 27 to 68 \\
\hline & & $0-17$ years & 440 & 10 & 2 & 370 & 13 & 4 & 83 & 54 to 94 \\
\hline ES & PC & $18-64$ years & 503 & 31 & 6 & 511 & 40 & 8 & 51 & 13 to 72 \\
\hline & & $\geq 65$ years & 79 & 31 & 39 & 66 & 22 & 33 & 15 & -114 to 66 \\
\hline & & Target group $^{\mathrm{a}}$ & 207 & 53 & 26 & 180 & 50 & 28 & 38 & -5 to 63 \\
\hline UK & $\mathrm{PC}$ & All ages & 209 & 33 & 16 & 910 & 190 & 21 & 54 & 24 to 72 \\
\hline & & All ages & 1,368 & 150 & 11 & 2,510 & 269 & 11 & 39 & 19 to 54 \\
\hline & & $0-17$ years & 562 & 21 & 4 & 980 & 35 & 4 & 58 & 15 to 79 \\
\hline EU-PC & PC & $18-64$ years & 643 & 55 & 9 & 1,279 & 108 & 8 & 27 & -9 to 51 \\
\hline & & $\geq 65$ years & 161 & 74 & 46 & 250 & 126 & 50 & 54 & 20 to 73 \\
\hline & & Target group ${ }^{\mathrm{a}}$ & 382 & 125 & 33 & 696 & 215 & 31 & 39 & 14 to 56 \\
\hline & & All ages & 2,298 & 437 & 19 & 8,896 & 2,299 & 26 & 36 & 27 to 44 \\
\hline DK & PC and hospital & $18-64$ years & 1,220 & 111 & 9 & 3,462 & 538 & 16 & 44 & 30 to 56 \\
\hline & & $\geq 65$ years & 701 & 319 & 46 & 3,089 & 1,688 & 55 & 28 & 14 to 39 \\
\hline EU-H & Hospital & $\geq 65$ years & 249 & 131 & 53 & 524 & 321 & 61 & 34 & 8 to 52 \\
\hline Influenza B/Yamagata & & & & & & & & & & \\
\hline $\mathrm{ES}$ & $\mathrm{PC}$ & All ages & 84 & 4 & 5 & 993 & 81 & 8 & 77 & 14 to 94 \\
\hline $\mathrm{EU}-\mathrm{PC}^{\mathrm{b}}$ & $\mathrm{PC}$ & All ages & 395 & 34 & 9 & 2,065 & 206 & 10 & 49 & 19 to 67 \\
\hline
\end{tabular}

CI: confidence interval; DK: Denmark study; ES: Spain study; EU-H: European hospital-based multi-country I-MOVE+study; EU-PC: European primary care-based multicountry I-MOVE/I-MOVE+study; PC: primary care; UK: United Kingdom study; Vacc: vaccinated; VE: vaccine effectiveness.

a Groups targeted by seasonal influenza vaccination as defined locally in the studies and study sites.

${ }^{b}$ Only includes study sites where lineage was available for all samples or where lineage was determined systematically.

Study sites included in the EU-H analysis: France, Italy, Navarra, the Netherlands, Portugal and Spain (except for influenza A(H3N2) analysis: Navarra and Spain only). Study sites included in EU-PC analysis for all influenza and influenza B: Croatia, France, Germany, Ireland, Italy, the Netherlands, Portugal, Spain, Sweden. For analysis against $A\left(\mathrm{H}_{1} \mathrm{~N}_{1}\right)$ pdmo9: France, Germany, Italy and Spain were included. For analysis against A(H3N2): France, Germany, Ireland, Spain and Sweden were included. 
TABLE 3

Influenza viruses characterised by clade and study site, Europe, influenza season 2017/18 ( $\mathrm{n}=886)$

\begin{tabular}{|c|c|c|c|c|c|c|c|c|c|}
\hline & \multirow{2}{*}{ Clade } & \multicolumn{2}{|c|}{ ES a } & \multicolumn{2}{|c|}{ UK } & \multicolumn{2}{|c|}{$E U-P C^{b}$} & \multicolumn{2}{|c|}{$\mathrm{DK}^{\mathrm{c}}$} \\
\hline & & $\mathrm{n}$ & $\%$ & $\mathrm{n}$ & $\%$ & $\mathrm{n}$ & $\%$ & $\mathrm{n}$ & $\%$ \\
\hline Total influenza $\mathrm{A}\left(\mathrm{H}_{1} \mathrm{~N}_{1}\right)$ & & \multicolumn{2}{|c|}{$\mathrm{n}=142$} & \multicolumn{2}{|c|}{$n=20$} & \multicolumn{2}{|c|}{$\mathrm{n}=469$} & \multicolumn{2}{|c|}{$\mathrm{n}=113$} \\
\hline Sequenced & & 28 & 100 & 10 & 100 & 25 & 100 & 23 & 100 \\
\hline A/Michigan/45/2015 & 6B.1 & 28 & 100 & 10 & 100 & 25 & 100 & 23 & 100 \\
\hline Total influenza $\mathrm{A}\left(\mathrm{H}_{3} \mathrm{~N}_{2}\right)$ & & \multicolumn{2}{|c|}{$n=233$} & \multicolumn{2}{|c|}{$\mathrm{n}=174$} & \multicolumn{2}{|c|}{$\mathrm{n}=229$} & \multicolumn{2}{|c|}{$\mathrm{n}=144$} \\
\hline Sequenced & & 51 & 100 & 59 & 100 & 43 & 100 & 51 & 100 \\
\hline A/HongKong/4801/2014 & $3 C .2 a$ & 20 & 39 & 46 & 78 & 27 & 63 & 36 & 71 \\
\hline A/Singapore/INFIMH-16-0019/2016 & $3 \mathrm{C} .2 \mathrm{a} 1$ & 31 & 61 & 10 & 17 & 16 & 37 & 15 & 29 \\
\hline A/Switzerland/9715293/2013 & $3 C .3 a$ & 0 & 0 & 3 & 5 & 0 & 0 & 0 & 0 \\
\hline Total influenza B & & \multicolumn{2}{|c|}{$n=1,022$} & \multicolumn{2}{|c|}{$\mathrm{n}=209$} & \multicolumn{2}{|c|}{$n=1,469$} & \multicolumn{2}{|c|}{$n=625$} \\
\hline Sequenced & & 164 & 100 & 116 & 100 & 207 & 100 & 109 & 100 \\
\hline B/Yamagata & & 136 & 83 & 116 & 100 & 198 & 96 & 109 & 100 \\
\hline B/Phuket/3073/2013 & 3 & 136 & 100 & 0 & 0 & 198 & 100 & 109 & 100 \\
\hline B/Victoria & & 28 & 17 & 0 & 0 & 9 & 4 & 0 & 0 \\
\hline B/Norway/2409/2017 & $1 \mathrm{~A} \Delta\left(\mathrm{K}_{162}, \mathrm{~N}_{163}\right)$ & 20 & 71 & 0 & 0 & 5 & 56 & 0 & 0 \\
\hline $\mathrm{B} /$ Brisbane $/ 60 / 2008$ & $1 \mathrm{~A}$ & 8 & 29 & 0 & 0 & 4 & 44 & 0 & 0 \\
\hline
\end{tabular}

50 specimens from ES are also included in EU-PC data.

b The specimens sequenced from Spain are originating from the entire National Influenza Surveillance System between weeks $44 / 2017$ and $03 / 2018$.

c Sequence information is based on a sub-sample of influenza-positive samples received for surveillance at the National Influenza Center Denmark from week 40/2017 to 4/2018.

2017 interim results from Australia [16], and as already reported in other published early estimates for the northern hemisphere [17], the VE against influenza $\mathrm{A}\left(\mathrm{H}_{3} \mathrm{~N}_{2}\right)$ was low in participating study sites. In our studies, $63 \%$ of sequenced influenza $A\left(\mathrm{H}_{3} \mathrm{~N}_{2}\right)$ viruses belonged to the $\mathrm{A} /$ HongKong/4801/2014 vaccine strain genetic group ( $3 \mathrm{C} .2 \mathrm{a}$ ) and $35 \%$ to the $\mathrm{A} / \mathrm{Singapore} /$ INFIMH-16-0019/2016 clade (3C.2a1), which is the selected strain in the 2018 southern hemisphere and 2018/19 northern hemisphere influenza vaccines [18]. Small sample size limited VE estimation by clade and subclade, which will be a priority for end-of-season analyses. Our results further support the need for more effective interventions in older people, in whom the burden of influenza $\mathrm{A}\left(\mathrm{H}_{3} \mathrm{~N}_{2}\right)$ is most notable and the VE, including against severe outcome, is the lowest [19]. Based upon recent cost-effectiveness work undertaken by Public Health England, the UK Joint Committee on Vaccination and Immunisation has advised that use of adjuvanted trivalent inactivated vaccines (TIV) in those aged 65 years and older would be both more effective and cost-effective than the non-adjuvanted trivalent or quadrivalent vaccines currently in use [20].

The interim VE against medically attended influenza B was moderate in the studies included here (36\% to 54\% among all ages), similar to recently published estimates from northern hemisphere countries $[17,21,22]$. It was moderate to good against medically attended influenza $B$ in children ( $58 \%$ in EU PC and $83 \%$ in ES) and poorer at $34 \%$ against hospitalised outcome among adults 65 years and older. The vast majority (94\%) of sequenced influenza B samples were of the B/Yamagata lineage, which was not included in the $2017 / 18$ northern hemisphere TIV. VE was $77 \%$ and $49 \%$ against influenza B/ Yamagata in the ES and EU-PC studies, respectively, suggesting important cross-lineage protection.

The UK study was the only one to provide VE estimates for the quadrivalent vaccines. Vaccine effectiveness against any influenza among children was similar in the UK study (53\%), where children receive LAIV4, and in the EU-PC study (59\%), where most vaccinated children received TIV. However, it is difficult to compare these estimates against any influenza since the relative proportion of circulating (sub)types was different in the UK, where there was a higher proportion of circulating influenza $A\left(\mathrm{H}_{3} \mathrm{~N}_{2}\right)$ viruses, compared with most countries participating in the EU-PC study. In past seasons where circulating and vaccine lineages were different, contradictory results were observed $[13,23,24]$. Partial, but not full cross-protection between mismatched influenza $B$ lineages has been suggested by two systematic reviews $[25,26]$. More precise end-of-season estimates by lineage, age group and vaccine type would be of added value to discuss cross-lineage protection and the added protection conferred by quadrivalent vaccines. Such information is relevant at a time when QIV is available in most European countries [27] and preferentially recommended in some [28].

End-of-season analyses are needed to verify the conclusions from these interim season results. A larger sample size should allow more precise estimates, 
especially in stratified analyses. Recent publications suggest a potentially strong (boosting or lowering) effect of previous vaccination on VE estimates $[29,30]$ and end-of-season analyses should take this into account. Although TND is a well-recognised study design to measure VE, we cannot rule out bias from unmeasured confounding.

These early VE results from five studies were included in the Global Influenza VE (GIVE) report to help inform the World Health Organization vaccine strain selection committee meeting on 22 February 2018. For the $2018 / 19$ northern hemisphere trivalent vaccine, this selection committee recommended to include the same influenza $A\left(\mathrm{H}_{1} \mathrm{~N}_{1}\right)$ component as in the $2017 / 18$ northern hemisphere vaccine, an A/Singapore/ INFIMH-16-0019/2016 ( $\left.\mathrm{H}_{3} \mathrm{~N}_{2}\right)$-like virus and $\mathrm{a} B$ / Colorado/06/2017-like virus (B/Victoria/2/87 lineage) [18].

In the context of an influenza season with co-circulation of influenza $A\left(\mathrm{H}_{3} \mathrm{~N}_{2}\right)$, influenza $A\left(\mathrm{H}_{1} \mathrm{~N}_{1}\right)$ pdmog and influenza $B$ viruses mismatched with the trivalent vaccine, results from these five EU studies indicate a moderate VE against all influenza. Vaccination continues to be the most effective preventive measure against influenza and uptake of the 2017/18 trivalent or quadrivalent influenza vaccines should still be promoted in countries with ongoing virus circulation. In particular in settings with evidence of influenza $\mathrm{A}\left(\mathrm{H}_{3} \mathrm{~N}_{2}\right)$ virus circulation, prophylactic use of antiviral drugs, administered according to country-specific guidelines, could help prevent severe outcomes [31]. Based on our results and in the absence of major antigenic drift, we may expect a good protection of the $2018 / 19$ northern hemisphere seasonal influenza vaccine against influenza $A\left(\mathrm{H}_{1} \mathrm{~N}_{1}\right)$ and $B$ viruses. Monitoring the effectiveness of the 2018 southern influenza vaccine against influenza $A\left(\mathrm{H}_{3} \mathrm{~N}_{2}\right)$ viruses will be important to prepare for the next influenza season in the northern hemisphere.

\section{I-MOVE/I-MOVE+ group}

\section{Croatia}

\section{EU-PC study:}

Bernard Kaic, Croatian Institute of Public Health, Zagreb

Sanja Kurecic Filipovic, Croatian Institute of Public Health, Zagreb

Vesna Visekruna-Vucina, Croatian Institute of Public Health, Zagreb

Iva Pem Novosel, Croatian Institute of Public Health, Zagreb

Zvjezdana Lovric, Croatian Institute of Public Health, Zagreb

Goranka Petrović, Croatian Institute of Public Health, Zagreb

Denmark

DK study:
Tyra Grove Krause, Department of Infectious Disease Epidemiology and Prevention, Statens Serum Institut, Artillerivej 5, 2300 Copenhagen S, Denmark

Thea Kølsen Fische, Department of Virus and Microbiological Special diagnostics, National Influenza Center, Statens Serum Institut, Artillerivej 5, 2300 Copenhagen S, Denmark

France

EU-PC and EU-H studies:

Bruno Lina, Laboratoire de Virologie, CNR des virus des infections respiratoires, Institut des Agents Infectieux, Groupement Hospitalier Nord des HCL, Lyon, France; Laboratoire Virpath, CIRI Inserm U1111, CNRS 5308, ENS, UCBL, Faculté de Médecine LYON Est, Université de Lyon, Lyon.

EU-PC study:

Alessandra Falchi, EA7310, Laboratoire de Virologie, Université de Corse-Inserm, FR- 20250, Corte, France

Ana-Maria Vilcu, Cécile Souty, Thierry Blanchon, Sorbonne Université, INSERM, Institut Pierre Louis d'Epidémiologie et de Santé Publique (IPLESP), F75012 Paris.

Sylvie van der Werf, Unité de Génétique Moléculaire des Virus à ARN, UMR 3569 CNRS, Université Paris Diderot SPC, Institut Pasteur, Paris; CNR des virus des infections respiratoires, Institut Pasteur, Paris

Vincent Enouf, Unité de Génétique Moléculaire des Virus à ARN, UMR 3569 CNRS, Université Paris Diderot SPC, Institut Pasteur, Paris ; CNR des virus des infections respiratoires, Institut Pasteur, Paris.

Sylvie Behillil, Unité de Génétique Moléculaire des Virus à ARN, UMR 3569 CNRS, Université Paris Diderot SPC, Institut Pasteur, Paris; CNR des virus des infections respiratoires, Institut Pasteur, Paris.

Martine Valette, Laboratoire de Virologie, CNR des virus des infections respiratoires, Institut des Agents Infectieux, Groupement Hospitalier Nord des HCL, Lyon.

Sibylle Bernard-Stoecklin, Santé publique France, Paris.

Daniel Lévy-Bruhl, Santé publique France, Paris.

EU-H study:

Odile Launay, Innovative clinical research network in vaccinology, I-REIVAC, CIC Cochin-Pasteur, Paris

Pierre Loulergue, I-REIVAC, CIC Cochin-Pasteur, Paris

Nezha Lenzi, I-REIVAC, Paris

Zineb Lesieur, I-REIVAC, Paris

Anne-Sophie L'Honneur, service de Virologie, Hôpital Cochin, Paris

Florence Galtier: CIC 1411, hôpital St Eloi, CHU de Montpellier ; Inserm, F-CRIN, I-REIVAC

Camille Agostini, CIC 1411, hôpital St Eloi, CHU de Montpellier

Chris Serrand, CIC 1411, hôpital St Eloi, CHU de Montpellier

Corinne Merle, Service des Maladies Infectieuses et Tropicales, Hôpital Gui de Chauliac, CHU de Montpellier

Vincent Foulongne, Pathogenesis and Control of Chronic Infections, Univ. Montpellier, INSERM, EFS, CHU Montpellier, Montpellier, France

Philippe Vanhems, I-REIVAC; Hôpital Edouard Herriot, Lyon 
Fabrice Lainé, I-REIVAC; CIC 1414, Hôpital Pontchaillou, Rennes

Gisèle Lagathu, laboratoire de virologie, C.H.U de Rennes

Fabrice Carrat, UPMC Univ Paris 06, IPLESP UMRS 1136, Public health department, Hôpital Saint-Antoine, Paris

Germany

EU-PC study:

Silke Buda, Department for Infectious Disease Epidemiology, Robert Koch Institute, Berlin

Ute Preuss, Department for Infectious Disease Epidemiology, Robert Koch Institute, Berlin

Kerstin Prahm, Department for Infectious Disease Epidemiology, Robert Koch Institute, Berlin

Brunhilde Schweiger, National Reference Center for Influenza, Robert Koch Institute, Berlin

Marianne Wedde, National Reference Center for Influenza, Robert Koch Institute, Berlin

Alla Heider, National Reference Center for Influenza, Robert Koch Institute, Berlin

Maria Martin, National Reference Center for Influenza, Robert Koch Institute, Berlin

Barbara Biere, National Reference Center for Influenza, Robert Koch Institute, Berlin

Ralf Duerrwald, National Reference Center for Influenza, Robert Koch Institute, Berlin

Ireland

EU-PC study:

Lisa Domegan, HSE-Health Protection Surveillance Centre, Dublin

Laura Coughlan, HSE-Health Protection Surveillance Centre, Dublin

Joan O’Donnell, HSE-Health Protection Surveillance Centre, Dublin

Michael Joyce, Irish College of General Practitioners, Dublin

Claire Collins, Irish College of General Practitioners, Dublin

Linda Dunford, National Virus Reference Laboratory, University College Dublin

Joanne Moran, National Virus Reference Laboratory, University College Dublin

Grainne Tuite, National Virus Reference Laboratory, University College Dublin

Margaret Duffy, National Virus Reference Laboratory, University College Dublin

Jeff Connell, National Virus Reference Laboratory, University College Dublin

Cillian de Gascun, National Virus Reference Laboratory, University College Dublin

Italy

Italian Influenza Surveillance System:

Caterina Rizzo, Istituto Superiore di Sanità, Rome

Antonino Bella, Istituto Superiore di Sanità, Rome
Valeria Alfonsi, Istituto Superiore di Sanità, Rome

Maria Rita Castrucci, National Influenza Center, Istituto Superiore di Sanità, Rome

Simona Puzelli, National Influenza Center, Istituto Superiore di Sanità, Rome

EU-PC study:

Elisabetta Pagani, Regional Reference Laboratory for influenza, TRENTINO ALTO ADIGE, Bolzano

Valeria Ghisetti, Regional Reference Laboratory for influenza, PIEMONTE

Elena Pariani, Regional Reference Laboratory for influenza, LOMBARDIA, Milano

Fausto Baldanti, Regional Reference Laboratory for influenza, LOMBARDIA, Pavia

Giorgio Palù, Regional Reference Laboratory for influenza, VENETO

Pierlanfranco D’Agaro, Regional Reference Laboratory for influenza, FRIULI VENEZIA GIULIA

Filippo Ansaldi, Regional Reference Laboratory for influenza, LIGURIA

Paola Affanni, Regional Reference Laboratory for influenza, EMILIA-ROMAGNA

Gian Maria Rossolini, Regional Reference Laboratory for influenza, TOSCANA

Barbara Camilloni, Regional Reference Laboratory for influenza, UMBRIA

Patrizia Bagnarelli, Regional Reference Laboratory for influenza, MARCHE

Maurizio Sanguinetti, Regional Reference Laboratory for influenza, LAZIO

Luigi Atripaldi, Regional Reference Laboratory for influenza, CAMPANIA

Maria Chironna, Regional Reference Laboratory for influenza, PUGLIA

Caterina Serra, Regional Reference Laboratory for influenza, SARDEGNA

Francesco Vitale, Regional Reference Laboratory for influenza, SICILIA

EU-H study:

Maria Chironna, Department of Biomedical Science and Human Oncology, Bari hospital, Bari

Cinzia Germinario, Department of Biomedical Science and Human Oncology, Bari hospital, Bari

Andrea Orsi, San Martino Polyclinic Hospital, University of Genoa, Genoa

Filippo Ansaldi, San Martino Polyclinic Hospital, University of Genoa, Genoa

Ilaria Manini, Department of Molecular and Developmental Medicine, University of Siena, Siena

Emanuele Montomoli, Department of Molecular and Developmental Medicine, University of Siena, Siena

Christian Napoli, Sant'Andrea Hospital, Sapienza University of Rome, Rome 
Giovanni Battista Orsi, Sant'Andrea Hospital, Sapienza University of Rome, Rome

Navarra:

EU-H study:

Itziar Casado, Instituto de Salud Pública de Navarra, IdiSNA, CIBERESP, Pamplona

Jesús Castilla, Instituto de Salud Pública de Navarra, IdiSNA, CIBERESP, Pamplona

Leticia Fernandino, Instituto de Salud Pública de Navarra, IdiSNA, CIBERESP, Pamplona

Iván Martínez-Baz, Instituto de Salud Pública de Navarra, IdiSNA, CIBERESP, Pamplona

Guillermo Ezpeleta, Instituto de Salud Pública de Navarra, IdiSNA, CIBERESP, Pamplona

Ana Navascués, Complejo Hospitalario de Navarra, IdiSNA, Pamplona

Alejandra Pérez-García, Complejo Hospitalario de Navarra, IdiSNA, Pamplona

Aitziber Aguinaga, Complejo Hospitalario de Navarra, IdiSNA, Pamplona

Carmen Ezpeleta, Complejo Hospitalario de Navarra, IdiSNA, Pamplona

The Netherlands

EU-PC and EU-H studies:

Adam Meijer, National Institute for Public Health and the Environment (RIVM), Bilthoven

Sharon van den Brink, National Institute for Public Health and the Environment (RIVM), Bilthoven

Wim van der Hoek, National Institute for Public Health and the Environment (RIVM), Bilthoven

Gabriel Goderski, National Institute for Public Health and the Environment (RIVM), Bilthoven

Lisa Wijsman, National Institute for Public Health and the Environment (RIVM), Bilthoven

EU-PC study:

Mariam Bagheri, National Institute for Public Health and the Environment (RIVM), Bilthoven

Frederika Dijkstra, National Institute for Public Health and the Environment (RIVM), Bilthoven

Marit de Lange, National Institute for Public Health and the Environment (RIVM), Bilthoven

Ton Marzec, National Institute for Public Health and the Environment (RIVM), Bilthoven

Pieter Overduin, National Institute for Public Health and the Environment (RIVM), Bilthoven

Anne Teirlinck, National Institute for Public Health and the Environment (RIVM), Bilthoven

Erny Wentink, Netherlands Institute for Health Services Research (NIVEL), Utrecht

Gé Donker, Netherlands Institute for Health Services Research (NIVEL), Utrecht

EU-H study:
Sierk Marbus, National Institute for Public Health and the Environment (RIVM), Bilthoven

Rianne van Gageldonk- Lafeber, National Institute for Public Health and the Environment (RIVM), Bilthoven

Peter Schneeberger, Jeroen Bosch Hospital, 's Hertogenbosch

Jan Jelrik van Oosterheert, University Medical Center Utrecht, Utrecht

Valentijn Schweitzer, University Medical Center Utrecht, Utrecht

Geert Groeneveld, Leiden University Medical Center, Leiden

Portugal

EU-PC and EU-H studies:

Baltazar Nunes, Departamento de Epidemiologia, Instituto Nacional de Saúde Dr. Ricardo Jorge, Lisbon

Ausenda Machado, Departamento de Epidemiologia, Instituto Nacional de Saúde Dr. Ricardo Jorge, Lisbon

Ana Paula Rodrigues, Departamento de Epidemiologia, Instituto Nacional de Saúde Dr. Ricardo Jorge, Lisbon

Verónica Gomez, Departamento de Epidemiologia, Instituto Nacional de Saúde Dr. Ricardo Jorge, Lisbon

Irina Kislaya, Departamento de Epidemiologia, Instituto Nacional de Saúde Dr. Ricardo Jorge, Lisbon

EU-PC study:

Raquel Guiomar, Departamento de Doenças Infeciosas, Instituto Nacional de Saúde Dr. Ricardo Jorge, Lisbon

Pedro Pechirra, Departamento de Doenças Infeciosas, Instituto Nacional de Saúde Dr. Ricardo Jorge, Lisbon

Paula Cristóvão, Departamento de Doenças Infeciosas, Instituto Nacional de Saúde Dr. Ricardo Jorge, Lisbon

Inês Costa, Departamento de Doenças Infeciosas, Instituto Nacional de Saúde Dr. Ricardo Jorge, Lisbon

EU-H study:

António Panarra, Centro Hospitalar de Lisboa Central, Lisbon Rita Côrte-Real, Centro Hospitalar de Lisboa Central, Lisbon José Poças, Centro Hospitalar de Setúbal, Setúbal

Maria João Peres, Centro Hospitalar de Setúbal, Setúbal

Spain

The cycEVA work group

Amparo Larrauri:, National Centre of Epidemiology, Institute of Health Carlos III, CIBERESP

Alin Gherasim, National Centre of Epidemiology, Institute of Health Carlos III, CIBERESP

Francisco Pozo, Inmaculada Casas National Centre for Microbiology, National Influenza Reference Laboratory,

HO-National Influenza Centre, Institute of Health Carlos III

Luis García Comas, Dirección General de Salud Pública, Comunidad de Madrid

María Esther Insua Marisquerena, Dirección General de Salud Pública, Comunidad de Madrid

Juan Carlos Galán, Laboratorio Hospital Ramón y Cajal 
Ma Dolores Folgueira, Laboratorio Hospital Doce de Octubre Fernando Gonzalez Carril, Departamento de Salud, Gobierno del País Vasco,

Rosa Sancho Martínez, Departamento de Salud, Gobierno del País Vasco

Gustavo Cilla Laboratorio Hospital Donostia, CIBERER

Jesús Castilla, Navarra Institute for Health Research IdiSNA, Pamplona, CIBERESP

Manuel García Cenoz, Navarra Institute for Health Research IdiSNA, Pamplona, CIBERESP

Ana Navascués, Complejo Hospitalario de Navarra

Carmen Quiñones Rubio, Dirección General de Salud Pública y Consumo de La Rioja

Eva Martinez Ochoa, Dirección General de Salud Pública y Consumo de La Rioja

Miriam Blasco, Laboratorio Hospital San Pedro de Logroño

Jaume Gimenez Duran, Servicio de Epidemiología, Dirección General de Salud Pública, Mallorca

Juana Maria Vanrell, Servicio de Epidemiología, Dirección General de Salud Pública, Mallorca

Jordi Reina, Laboratorio del Hospital Son Espases, Mallorca

Daniel Castrillejo, Servicio de Epidemiología. DGSC, Consejería de Bienestar Social y Sanidad, Ciudad Autónoma

e Melilla

The Spanish Influenza Sentinel Surveillance System:

Amparo Larrauri, National Centre of Epidemiology, Institute of Health Carlos III, CIBERESP

Alin Manuel Gherasim, National Centre of Epidemiology, Institute of Health Carlos III, CIBERESP

Concha Delgado, National Centre of Epidemiology, Institute of Health Carlos III, CIBERESP

Jesus Oliva National Centre of Epidemiology, Institute of Health Carlos III, CIBERESP Francisco Pozo, National Centre for Microbiology, National Influenza Reference Laboratory, WHO-National Influenza Centre, Institute of Health Carlos III.

Inmaculada Casas, National Centre for Microbiology, National Influenza Reference Laboratory, WHO-National Influenza Centre, Institute of Health Carlos III.

The Spanish IMOVE+ study: the hospitals component:

Amparo Larrauri, National Centre of Epidemiology, Institute of Health Carlos III, CIBERESP

Alin Manuel Gherasim, National Centre of Epidemiology, Institute of Health Carlos III, CIBERESP

Francisco Pozo, National Centre for Microbiology, National Influenza Reference Laboratory, WHO-National Influenza Centre, Institute of Health Carlos III.

Inmaculada Casas, National Centre for Microbiology, National Influenza Reference Laboratory, WHO-National Influenza Centre, Institute of Health Carlos III.

Miriam García Dirección General de Salud Pública, Aragón;

Miriam Latorre, Hospital Universitario Miguel Servet, Zaragoza

Ana María Milagro Beamonte, Hospital Universitario Miguel Servet, Zaragoza
Ana Martinez Sapiña, Hospital Universitario Miguel Servet, Zaragoza

Madalen Oribe Amores, Subdirección de Salud Pública Gipuzkoa, País Vasco

Amaia Aizpurúa, Laboratorio Hospital Donostia, CIBERER

Gustavo Cilla, Laboratorio Hospital Donostia, CIBERER

Milagrosa Montes, Laboratorio Hospital Donostia, CIBERER

Sweden

EU-PC study:

Katherina Zakikhany, The Public Health Agency of Sweden, Stockholm

Mia Brytting, The Public Health Agency of Sweden, Stockholm

Åsa Wiman, The Public Health Agency of Sweden, Stockholm

Annasara Carnahan, The Public Health Agency of Sweden, Stockholm

United Kingdom

UK study:

Richard Pebody, Public Health England, London

Fiona Warburton, Public Health England, London Abdelmajid Djennad, Public Health England, London

Joanna Ellis, Public Health England, London

Nick Andrews, Public Health England, London

Diogo Marques, Health Protection Scotland, Glasgow

Simon Cottrell, Public Health Wales, Cardiff

Arlene Reynolds, Health Protection Scotland, Glasgow

Rory Gunson, West of Scotland Specialist Virology Centre, Glasgow

Monica Galiano, Public Health England, London

Angie Lackenby, Public Health England, London

Chris Robertson, University of Strathclyde, Glasgow

Mark O’Doherty, Public Health Agency Northern Ireland, Belfast

Mary Sinnathamby, Public Health England, London

Ivelina Yonova, University of Surrey, Guildford, Royal College of General Practitioners, London

Catherine Moore, Public Health Wales, Cardiff

Muhammed Sartaj, Public Health Agency Northern Ireland, Belfast

Simon de Lusignan, University of Surrey, Guildford, Royal College of General Practitioners, London

Jim McMenamin, Health Protection Scotland, Glasgow

Maria Zambon, Public Health England, London

EpiConcept

EU-PC and EU-H studies: Marta Valenciano, Alain Moren, EpiConcept, Paris

EU-PC study: Esther Kissling, EpiConcept, Paris 
EU-H study: Marc Rondy, EpiConcept, Paris

European Centre for Disease Prevention and Control (ECDC)

Pasi Penttinen, European Centre for Disease Prevention and Control

\section{Acknowledgements}

Funding: The five studies have received funding from the European Union's Horizon 2020 research and innovation programme under grant agreement No 634446 to conduct the study in individuals aged 65 years or more. ECDC has contributed to fund some study sites of the EU-PC study under the Framework contract No ECDC/2014/026 for the individuals aged less than 65 years. All study teams are very grateful to all patients, general practitioners, paediatricians, hospital teams, laboratory teams, regional epidemiologists who have contributed to the studies. We acknowledge the authors, originating and submitting laboratories of the sequences from GISAID's EpiFlu Database used for this study. All submitters of data may be contacted directly via the GISAID website www.gisaid.org

\section{Conflict of interest}

\section{None}

\section{Authors' contributions}

Marc Rondy: coordination I-MOVE+ hospital network, study design, analysis of hospital data, interpretation of results, manuscript writing. Esther Kissling: coordination I-MOVE/IMOVE+ primary care network, study design, analysis of primary care data, interpretation of results, manuscript writing. Both authors contributed equally to the study and manuscript. Hanne-Dorthe Emborg, Alin Gherasim, Richard Pebody, Ramona Trebbien, Amparo Larrauri and Jim McMenamin: coordination of their respective studies, data analysis and interpretation of results. Read, contributed to and approved the final version of the manuscript. Francisco Pozo: coordinated the I-MOVE/I-MOVE+ virological analysis of the primary care study. European IVE group: Primary care and hospital sites at national/regional level: data collection, data validation, results interpretation, review of manuscript. Laboratories: virological analysis, genetic characterisation, interpretation of results, review of manuscript. Alain Moren, Marta Valenciano: study design, coordination of I-MOVE/I-MOVE+ network, interpretation of results, contribution to manuscript writing. Pasi Penttinen: study design, interpretation of results, review of manuscript.

\section{Reference}

1. European Centre for Disease Prevention and Control (ECDC) Seasonal influenza vaccination and antiviral use in Europe. Overview of vaccination recommendations and coverage rates in the EU Member States for the 2013-14 and 2014-15 influenza seasons. VENICE technical report [Internet]. Stockholm: ECDC; 2016. Available from: http://venice.cineca.org/Seasonalinfluenza-vaccination-antiviral-use-europe.pdf

2. Hakin B, Cosford P, Harvey F. The flu immunisation programme 2013/14- extension to children. London: Department of Health; 2013. Available from: https://www.gov.uk/government/ uploads/system/uploads/attachment_data/file/225360/ Children_s flu letter_2013.pdf

3. World Health Organization (WHO). Recommended composition of influenza virus vaccines for use in the 2017-2018 northern hemisphere influenza season. Geneva: WHO; 2017. Available from: http://www.who.int/influenza/vaccines/virus/ recommendations/2017_18_north/en/
4. European Centre for Disease Prevention and Control (ECDC), World Health Organization Regional Office for Europe (WHO/ Europe). Flu News Europe. Summary week 7/2018 (12-18 February 2018). Stockholm: ECDC, Copenhagen: WHO/Europe; 2018. Available from: http://flunewseurope.org/Archives

5. I-MOVE+. Protocol for hospital-based test negative case control studies to measure seasonal influenza vaccine effectiveness against influenza laboratory confirmed SARI hospitalisation among the elderly across the European Union and European Economic Area Member States. Paris: EpiConcept; 2016. Available from: https://drive.google.com/ file/d/oB54XpZN4SY650GRSTHIvOVZTMFE/view

6. European Centre for Disease Prevention and Control (ECDC). Protocol for case control studies to measure pandemic and seasonal vaccine effectiveness in the European Union and European Economic Area. Stockholm: ECDC; 2009. Available from: https://ecdc.europa.eu/sites/portal/files/media/en/ publications/Publications/0907_TED_Influenza_AH1N1_ Measuring_Influenza_Vaccine_Effectiveness_Protocol_Case_ Control_Studies.pdf

7. Jimenez-Jorge S, de Mateo S, Delgado-Sanz C, Pozo F, Casas I, Garcia-Cenoz M, et al. Estimating influenza vaccine effectiveness in Spain using sentinel surveillance data. Euro Surveill. 2015;20(28):21187. https://doi.org/10.2807/15607917.ES2015.20.28.21187 PMID: 26212144

8. Pebody R, Warburton F, Ellis J, Andrews N, Potts A, Cottrell S, et al. Effectiveness of seasonal influenza vaccine for adults and children in preventing laboratory-confirmed influenza in primary care in the United Kingdom: $2015 / 16$ end-of-season results. Euro Surveill. 2016;21(38):30348. https://doi. org/10.2807/1560-7917.ES.2016.21.38.30348 PMID: 27684603

9. Emborg HD, Krause TG, Nielsen L, Thomsen MK, Christiansen CB, Skov MN, et al. Influenza vaccine effectiveness in adults 65 years and older, Denmark, 2015/16 - a rapid epidemiological and virological assessment. Euro Surveill. 2016;21(14):30189. https://doi.org/10.2807/1560-7917.ES.2016.21.14.30189 PMID: 27101732

10. Rodrigues L, Kirkwood BR. Case-control designs in the study of common diseases: updates on the demise of the rare disease assumption and the choice of sampling scheme for controls. Int J Epidemiol. 1990;19(1):205-13. https://doi.org/10.1093/ ije/19.1.205 PMID: 2190942

11. Peduzzi P, Concato J, Kemper E, Holford TR, Feinstein AR. A simulation study of the number of events per variable in logistic regression analysis. J Clin Epidemiol. 1996;49(12):13739. https://doi.org/10.1016/So895-4356(96)00236-3 PMID: 8970487

12. Belongia EA, Simpson MD, King JP, Sundaram ME, Kelley NS, Osterholm MT, et al. Variable influenza vaccine effectiveness by subtype: a systematic review and meta-analysis of testnegative design studies. Lancet Infect Dis. 2016;16(8):94251. https://doi.org/10.1016/S1473-3099(16)00129-8 PMID: 27061888

13. Kissling E, Valenciano M, Pozo F, Vilcu A-M, Reuss A, Rizzo C, et al. 2015/16 I-MOVE/I-MOVE+ multicentre case control study in Europe: moderate vaccine effectiveness estimates against influenza $\mathrm{A}\left(\mathrm{H}_{1} \mathrm{~N}_{1}\right)$ pdmog and low estimates against lineage mismatched influenza B among children. Influenza Other Respir Viruses. 2017;2017. PMID: 29125681

14. World Health Organization (WHO). Recommended composition of influenza virus vaccines for use in the 2016-2017 northern hemisphere influenza season. Geneva: WHO; 2016. Available from: http://www.who.int/influenza/vaccines/virus/ recommendations/2016_17_north/en/

15. Rondy M, Gherasim A, Casado I, Launay O, Rizzo C, Pitigo $D$, et al. Low 2016/17 season vaccine effectiveness against hospitalised influenza $\mathrm{A}\left(\mathrm{H}_{3} \mathrm{~N}_{2}\right)$ among elderly: awareness warranted for 2017/18 season. Euro Surveill. 2017;22(41):1700645. https://doi.org/10.2807/1560-7917.ES.2017.22.41.1700645 PMID: 29043961

16. Sullivan SG, Chilver MB, Carville KS, Deng Y-M, Grant KA, Higgins G, et al. Low interim influenza vaccine effectiveness, Australia, 1 May to 24 September 2017. Euro Surveill. 2017;22(43):17-00707. https://doi.org/10.2807/1560-7917. ES.2017.22.43.17-00707 PMID: 29090681

17. Skowronski DM, Chambers C, De Serres G, Dickinson JA, Winter A-L, Hickman R, et al. Early season co-circulation of influenza $A\left(\mathrm{H}_{3} \mathrm{~N}_{2}\right)$ and $\mathrm{B}$ (Yamagata): interim estimates of $2017 / 18$ vaccine effectiveness, Canada, January 2018. Euro Surveill. 2018;23(5):18-00035. https://doi.org/10.2807/15607917.ES.2018.23.5.18-00035 PMID: 29409570

18. World Health Organization (WHO). Recommended composition of influenza virus vaccines for use in the 2018-2019 northern hemisphere influenza season. Geneva: WHO; 2018. Available from: http://www.who.int/influenza/vaccines/virus/ recommendations $/ 201802$ recommendation.pdf?ua $=1$ 
19. Rondy M, El Omeiri N, Thompson MG, Levêque A, Moren A, Sullivan SG. Effectiveness of influenza vaccines in preventing severe influenza illness among adults: A systematic review and meta-analysis of test-negative design case-control studies. J Infect. 2017;75(5):381-94. https://doi.org/10.1016/j. jinf.2017.09.010 PMID: 28935236

20. Public Health England (PHE). Summary of data to support the choice of influenza vaccination for adults in primary care. London: PHE; 2018. Available from: https://www.gov.uk/ government/publications/flu-vaccination-supporting-datafor-adult-vaccines/summary-of-data-to-support-the-choice-ofinfluenza-vaccination-for-adults-in-primary-care

21. Flannery B, Chung JR, Belongia EA, McLean HQ, Gaglani $M$, Murthy K, et al. Interim Estimates of 2017-18 Seasonal Influenza Vaccine Effectiveness - United States, February 2018. MMWR Morb Mortal Wkly Rep. 2018;67(6):180-5. https://doi. org/10.15585/mmwr.mm6706a2 PMID: 29447141

22. Castilla J, Navascués A, Casado I, Pérez-García A, Aguinaga A, Ezpeleta G, et al. Interim effectiveness of trivalent influenza vaccine in a season dominated by lineage mismatched influenza B, northern Spain, 2017/18. Euro Surveill. 2018;23(7):18-00057. https://doi.org/10.2807/1560-7917. ES.2018.23.7.18-00057 PMID: 29471624

23. Skowronski DM, Janjua NZ, Sabaiduc S, De Serres G, Winter A-L, Gubbay JB, et al. Influenza A/subtype and B/lineage effectiveness estimates for the 2011-2012 trivalent vaccine: cross-season and cross-lineage protection with unchanged vaccine. J Infect Dis. 2014;210(1):126-37. https://doi. org/10.1093/infdis/jiuo48 PMID: 24446529

24. Rondy M, Larrauri A, Casado I, Alfonsi V, Pitigoi D, Launay 0 , et al. 2015/16 seasonal vaccine effectiveness against hospitalisation with influenza $A\left(\mathrm{H}_{1} \mathrm{~N}_{1}\right)$ pdmog and $B$ among elderly people in Europe: results from the I-MOVE+ project. Euro Surveill. 2017;22(30):30580. https://doi. org/10.2807/1560-7917.ES.2017.22.30.30580 PMID: 28797322

25. Tricco AC, Chit A, Soobiah C, Hallett D, Meier G, Chen MH, et al. Comparing influenza vaccine efficacy against mismatched and matched strains: a systematic review and meta-analysis. BMC Med. 2013;11(1):153. https://doi.org/10.1186/1741-7015-11-153 PMID: 23800265

26. DiazGranados CA, Denis M, Plotkin S. Seasonal influenza vaccine efficacy and its determinants in children and nonelderly adults: a systematic review with meta-analyses of controlled trials. Vaccine. 2012;31(1):49-57. https://doi. org/10.1016/j.vaccine.2012.10.084 PMID: 23142300

27. European Centre for Disease Prevention and Control (ECDC). Types of seasonal influenza vaccine. Stockholm: ECDC. [Accessed 28 Feb 2018]. Available from: https://ecdc.europa. eu/en/seasonal-influenza/prevention-and-control/vaccines/ types-of-seasonal-influenza-vaccine

28. Impfkommission S. (STIKO). Wissenschaftliche Begründung für die Empfehlung des quadrivalenten saisonalen Influenzaimpfstoffs. [Scientific reason for recommending the quadrivalent seasonal influenza vaccine]. Epidemiologisches Bulletin. 2018;2. German. Available from: https://www.rki.de/ DE/Content/Infekt/EpidBull/Archiv/2018/Ausgaben/02_18. pdf?_blob=publicationFile

29. Belongia EA, Skowronski DM, McLean HQ, Chambers C, Sundaram ME, De Serres G. Repeated annual influenza vaccination and vaccine effectiveness: review of evidence. Expert Rev Vaccines. 2017;16(7):1-14. https://doi.org/10.1080/ 14760584.2017.1334554 PMID: 28562111

30. Rondy M, Launay O, Castilla J, Costanzo S, Puig-Barberà J, Gefenaite G, et al. InNHOVE/I-MOVE+working group. Repeated seasonal influenza vaccination among elderly in Europe: Effects on laboratory confirmed hospitalised influenza. Vaccine. 2017;35(34):4298-306. https://doi.org/10.1016/j. vaccine.2017.06.088 PMID: 28709555

31. European Centre for Disease Prevention and Control (ECDC). Expert opinion on neuraminidase inhibitors for the prevention and treatment of influenza - review of recent systematic reviews and meta-analyses. Stockholm: ECDC; 2017. Available from: https://ecdc.europa.eu/sites/portal/files/documents/ Scientific-advice-neuraminidase-inhibitors-2017.pdf

\section{License and copyright}

This is an open-access article distributed under the terms of the Creative Commons Attribution (CC BY 4.0) Licence. You may share and adapt the material, but must give appropriate credit to the source, provide a link to the licence, and indicate if changes were made.

This article is copyright of the authors, 2018. 